\title{
Dermoscopic Predictors of Tumor Thickness in Cutaneous Melanoma: A Retrospective Analysis of 245 Melanomas
}

\author{
Enrique Rodríguez-Lomba ${ }^{1}$, Belén Lozano-Masdemont ${ }^{2}$, Lula María Nieto-Benito ${ }^{1}$, Elisa Hernández \\ de la Torre ${ }^{1}$, Ricardo Suárez-Fernández ${ }^{1}$, José Antonio Avilés-Izquierdo ${ }^{1}$
}

1 Department of Dermatology, Hospital General Universitario Gregorio Marañón, Madrid, Spain

2 Department of Dermatology, Hospital Universitario de Móstoles, Madrid, Spain

Key words: melanoma, Breslow index, tumor thickness, dermoscopy, dermatoscopy, epiluminescence microscopy

Citation: Rodríguez-Lomba E, Lozano-Masdemont B, Nieto-Benito LM, Hernández de la Torre E, Suárez-Fernández R, Avilés-Izquierdo JA. Dermoscopic predictors of tumor thickness in cutaneous melanoma: a retrospective analysis of 245 melanomas. Dermatol Pract Concept. 2021;11(3):e2021059. DOI: https://doi.org/10.5826/dpc.1103a59

Accepted: December 23, 2020; Published: May 20, 2021

Copyright: @2021 Rodríguez-Lomba et al. This is an open-access article distributed under the terms of the Creative Commons Attribution License BY-NC-4.0, which permits unrestricted noncommercial use, distribution, and reproduction in any medium, provided the original authors and source are credited.

Funding: None.

Competing interests: The authors have no conflicts of interest to disclose.

Authorship: All authors have contributed significantly to this publication.

Corresponding author: Enrique Rodríguez-Lomba, MD, Department of Dermatology, Hospital General Universitario Gregorio Marañón, C/ Dr. Esquerdo, 46 - 28007 Madrid, Spain. Email: enriquerlomba@outlook.com

\footnotetext{
ABSTRACT Introduction: The literature regarding the association of dermoscopic structures with Breslow thickness in melanoma is scarce, limited to small case series, and mostly outdated.

Objective: This study determined the dermoscopic patterns, colors and structures that are associated with melanoma in situ, thin melanomas $(<0.8 \mathrm{~mm})$ and thick melanomas potentially requiring sentinel lymph node biopsy according to current guidelines $(\geq 0.8 \mathrm{~mm})$.

Methods: A retrospective evaluation of 245 dermoscopic images of primary cutaneous melanoma located on the trunk or limbs was performed by consensus of 2 dermoscopists.

Results: Red-pink, blue-gray and white color, blue-white veil, shiny white streaks, irregular vessels, blue-black pigmentation, milky red areas, pseudolacunae, ulceration and rainbow pattern were associated with thickness $\geq 0.8 \mathrm{~mm}$, whereas atypical pigmented network, regression and hypopigmented areas were significantly associated with early melanomas.

Limitations: This is a retrospective study performed in a single institution. Melanomas of special sites were excluded from our evaluation. Dermoscopy is based on subjective evaluations that depend largely on the observers' experience.

Conclusions: The identification of certain dermoscopic structures and colors might help in the discrimination between thin and thick melanomas.
} 


\section{Introduction}

The literature regarding the association of patterns, colors and dermoscopic structures with Breslow thickness in melanoma is scarce, limited to small case series, and mostly based on outdated nomenclature [1-5]. Certain specific dermoscopic structures could help in the early identification of melanomas with tumor thickness $\geq 0.8 \mathrm{~mm}$, potentially eligible for sentinel lymph node biopsy according to current guidelines. On the other hand, one author [6] recently criticized the established recommendation of re-excision of clinical safety margins in thin melanomas that have already been completely excised. According to them, a "personalized excision" approach would be preferable and should be included in future guidelines [6]. Dermoscopy could be useful in the identification of sharply confined melanomas with a high probability of tumor thickness $<0.8 \mathrm{~mm}$, allowing us to excise them in a single surgical procedure with adjusted margins. The aim of this study was to determine the dermoscopic colors and structures that are associated with both early melanomas $(<0.8 \mathrm{~mm})$ and thick melanomas $(\geq 0.8 \mathrm{~mm})$.

\section{Materials and Methods}

A retrospective evaluation of 245 dermoscopic images of primary cutaneous melanoma was performed. All the dermoscopic images were collected from the database of the Melanoma Unit in our department. These were obtained using a digital microscopy system comprising a DermLite Photo II Pro HR dermoscopy lens [3Gen] on an E-420 camera (Olympus). The lesion diameter had to be small enough to fit in the whole picture in order to qualify for inclusion. We excluded cases without histopathological confirmation, cases with melanoma metastases, as well as primary melanomas of special sites (facial, acral, nail, genital or mucosal melanoma). Images with thick hair density, blood or scales that impeded an adequate dermoscopic evaluation were also excluded. Clinical and histopathological data was obtained from patients' records and included age at diagnosis, sex, anatomical location of the tumor, and tumor diameter, palpability, and Breslow thickness.

A list of the dermoscopic criteria established by previous publications was evaluated by consensus of 2 blinded expert dermoscopists (J.A.A.I., E.R.L). The following dermoscopic features were analyzed: colors (light brown, dark brown, black, blue-gray, red-pink, white), asymmetry of color and structures, atypical pigmented network, irregular globules, streaks, irregular blotches, shiny white streaks, negative pigment network, blue-white veil, hypopigmented areas, prominent skin markings, structureless brown areas, blue-black pigmentation, milky red areas, rainbow pattern, pseudolacunae, ulceration, and irregular vessels.
Data were analyzed using SPSS version 22.0 (32-bits edition). Univariate analysis for qualitative variables was performed using Pearson's chi-square test and Fisher's exact test. A P value less than .05 was considered statistically significant. Sensitivity, specificity, positive predictive value (PPV) and negative predictive value (NPV) were calculated using $2 \times 2$ contingency tables. The odds ratio $(\mathrm{OR})$ was calculated for all variables with a confidence interval of $95 \%(95 \% \mathrm{CI})$.

\section{Results}

A total of 245 melanomas were analyzed. Three subtypes were initially defined: melanoma in situ (intraepidermal), thin melanomas (Breslow thickness $<0.8 \mathrm{~mm}$ ), and thick melanomas (Breslow thickness $\geq 0.8 \mathrm{~mm}$ ). The number of cases in each of these groups was $52(21.2 \%), 98(40.0 \%)$, and 95 $(38.7 \%)$, respectively. The mean Breslow thickness was 0.98 $\mathrm{mm}$ (range, 0-9.00 mm). The median Breslow thickness was $0.60 \mathrm{~mm}$, and only 23 melanomas $(9.3 \%$ ) had a Breslow thickness larger than $1.5 \mathrm{~mm}$.

Clinical and epidemiological features are presented in Table 1. Tumor diameter and palpability were the only clinical variables that showed statistically significant differences $(\mathrm{P}$ $=.001$ for both). All in situ melanomas were non-palpable. Less than half of the $<0.8 \mathrm{~mm}$ melanomas were clinically raised ( $\mathrm{n}=46 ; 46.9 \%$ ), while most of the $\geq 0.8 \mathrm{~mm}$ melanomas were palpable $(\mathrm{n}=86 ; 90.5 \%)$. Thick melanomas were more frequently larger than $10 \mathrm{~mm}(73.6 \%)$ than were thin melanomas $(50.0 \%)$ and melanoma in situ $(48.1 \%)$. There were no significant differences in age at diagnosis (mean ages, $59.13,57.55$ and 59.19 years, respectively) or sex distribution among the groups. Melanoma in situ and thin melanomas were slightly more frequent in women $(53.8 \%$ and $53.1 \%$, respectively), while thick melanomas were more prevalent in men $(53.7 \%)$. Most of the melanomas were located in areas of intermittent sun exposure $(\mathrm{n}=225 ; 91.8 \%)$ due to the exclusion criteria in our study design.

Table 2 summarizes the frequencies of colors and dermoscopic structures within each group. Light brown color was more frequent in early melanomas (melanoma in situ and thin melanoma), while blue-gray, red-pink or white color was more commonly observed in thick melanomas $(\mathrm{P}<.05)$. The presence of three or more colors showed no significant difference between groups. Early melanomas presented a higher frequency of atypical pigmented network, regression and hypopigmented areas. Shiny white streaks, blue-white veil, blue-black pigmentation, milky red areas, rainbow pattern, pseudolacunae, ulceration, irregular vessels and polymorphous vascular pattern were more frequent in thick melanomas $(\mathrm{P}<.05)$. No significant differences were observed in color or structure asymmetry between the three groups. 
Table 1. Clinical and Epidemiological Features, by Tumor Thickness

\begin{tabular}{|c|c|c|c|c|}
\hline Feature & $\begin{array}{c}\text { Melanoma in situ ( } \mathrm{n} \\
=52 \text { ) }\end{array}$ & $\begin{array}{c}\text { Melanoma }<0.8 \mathrm{~mm} \\
\qquad(\mathrm{n}=98)\end{array}$ & $\begin{array}{c}\text { Melanoma } \geq 0.8 \mathrm{~mm} \\
\qquad(\mathrm{n}=95)\end{array}$ & $\mathbf{P}$ \\
\hline Mean age, $y$ & 59.13 & 57.55 & 59.19 & NS \\
\hline$\geq 65$ y, n (\%) & $23(44.2)$ & $43(43.9)$ & $43(45.3)$ & NS \\
\hline Male:Female, n (\%) & $24: 28(46.2: 53.8)$ & $46: 52(46.9: 53.1)$ & $51: 44(53.7: 46.3)$ & NS \\
\hline Palpability, n (\%) & $0(0)$ & $46(46.9)$ & $86(90.5)$ & .001 \\
\hline Tumor diameter $\geq 10 \mathrm{~mm}, \mathrm{n}(\%)$ & $25(48.1)$ & $49(50.0)$ & $70(73.6)$ & .001 \\
\hline Tumor location, n (\%) & & & & NS \\
\hline Chronic exposure & $5(9.6)$ & $7(7.1)$ & $2(2.1)$ & \\
\hline Intermittent exposure & $45(86.5)$ & $89(90.8)$ & $91(95.8)$ & \\
\hline \multicolumn{5}{|l|}{ Non-exposed areas } \\
\hline & $2(3.8)$ & $2(2.0)$ & $2(2.1)$ & \\
\hline
\end{tabular}

NS = Not significant.

Table 2. Frequencies of Colors and Dermoscopic Structures, by Tumor Thickness

\begin{tabular}{|c|c|c|c|c|}
\hline Feature & $\begin{array}{l}\text { Melanoma in situ } \\
\qquad(n=52)\end{array}$ & $\begin{array}{c}\text { Melanoma }<0.8 \mathrm{~mm} \\
(\mathrm{n}=98)\end{array}$ & $\begin{array}{c}\text { Melanoma } \geq 0.8 \mathrm{~mm} \\
(\mathrm{n}=95)\end{array}$ & $\mathbf{P}$ \\
\hline $\begin{array}{l}\text { Color } \\
\text { Light brown }\end{array}$ & $50(96.2)$ & $93(94.9)$ & $78(82.1)$ & .003 \\
\hline Dark brown & $49(94.2)$ & $92(93.9)$ & $79(83.2)$ & .240 \\
\hline Black & $34(65.4)$ & $47(48.0)$ & $55(57.9)$ & .104 \\
\hline Blue-gray & $22(42.3)$ & $58(59.2)$ & $77(81.1)$ & .000 \\
\hline Red-pink & $6(11.5)$ & $22(22.4)$ & $49(51.6)$ & .000 \\
\hline $\begin{array}{l}\text { White } \\
\text { Three or more colors }\end{array}$ & $\begin{array}{r}6(11.5) \\
42(80.8)\end{array}$ & $\begin{array}{l}23(23.5) \\
81(82.7)\end{array}$ & $\begin{array}{l}41(43.2) \\
84(88.4)\end{array}$ & $\begin{array}{l}.000 \\
.383\end{array}$ \\
\hline Atypical pigmented network & $36(69.2)$ & $41(41.8)$ & $33(34.7)$ & .000 \\
\hline Irregular globules & $22(42.3)$ & $51(52.0)$ & $37(38.9)$ & .172 \\
\hline Irregular blotches & $22(42.3)$ & $54(55.1)$ & $40(42.1)$ & .139 \\
\hline Regression & $21(40.4)$ & $47(48.0)$ & $24(25.3)$ & .004 \\
\hline Shiny white streaks & $9(17.3)$ & $35(35.7)$ & $52(54.7)$ & .000 \\
\hline Hypopigmented areas & $8(15.4)$ & $15(15.3)$ & $6(6.3)$ & .104 \\
\hline Streaks & $7(13.5)$ & $23(23.5)$ & $18(18.9)$ & .333 \\
\hline Prominent skin markings & $6(11.5)$ & $7(7.1)$ & $5(5.3)$ & .376 \\
\hline Structureless brown areas & $5(9.6)$ & $13(13.3)$ & $15(15.8)$ & .576 \\
\hline Blue-white veil & $4(7.7)$ & $17(17.3)$ & $55(57.9)$ & .000 \\
\hline Negative pigment network & $4(7.7)$ & $7(7.1)$ & $7(7.4)$ & .992 \\
\hline Irregular vessels & $4(7.7)$ & $21(21.4)$ & $41(43.2)$ & .000 \\
\hline Blue-black pigmentation & $3(5.8)$ & $5(5.1)$ & $18(18.9)$ & .003 \\
\hline Milky red areas & $2(3.8)$ & $14(14.3)$ & $34(35.8)$ & .000 \\
\hline Ulceration & $0(0)$ & $4(4.1)$ & $35(36.8)$ & .000 \\
\hline Rainbow pattern & $0(0)$ & $6(6.1)$ & $25(26.3)$ & .000 \\
\hline Pseudolacunae & $0(0)$ & $3(3.1)$ & $23(24.2)$ & .000 \\
\hline
\end{tabular}

Two cohorts were grouped for the calculation of sensitivity, specificity, PPV, NPV and OR: early melanomas ( $\mathrm{n}=$ $150)$ and thick melanomas $(n=95)$. Results are presented in Table 3. The presence of three or more colors presented the highest sensitivity $(88.4 \%$ ) for a thickness $\geq 0.8 \mathrm{~mm}$, although most of the criteria showed sensitivity values lower than $50 \%$. Most of the criteria showed higher than $80 \%$ specificity for $\geq 0.8 \mathrm{~mm}$ tumor thickness. The highest specificity was obtained for pseudolacunae $(98.0 \%)$, ulceration $(96.7 \%)$ and rainbow pattern $(95.3 \%)$. PPV was highest for 
Table 3. Diagnostic Accuracy of Colors and Dermoscopic Structures for Tumor Thickness $\geq 0.8 \mathrm{~mm}$

\begin{tabular}{|c|c|c|c|c|c|}
\hline Feature & Sens. & Spec. & PPV & NPV & OR $(95 \% \mathrm{Cl})$ \\
\hline $\begin{array}{l}\text { Color } \\
\text { Red-pink }\end{array}$ & 51.6 & 81.3 & 63.6 & 72.6 & $4.641(2.611-8.242)$ \\
\hline Blue-gray & 46.7 & 81.1 & 49.0 & 79.5 & $3.743(2.044-6.853)$ \\
\hline White & 43.2 & 80.7 & 58.6 & 69.1 & $3.168(1.785-5.626)$ \\
\hline Black & 57.9 & 46.0 & 40.4 & 63.3 & $1.123(0.632-1.965)$ \\
\hline Dark brown & 83.2 & 6.0 & 35.9 & 36.0 & $0.315(0.133-0.740)$ \\
\hline Light brown & 82.1 & 4.7 & 35.3 & 29.2 & $0.225(0.081-0.562)$ \\
\hline Three or more colors & 88.4 & 18.0 & 40.6 & 71.1 & $1.676(0.789-3.563)$ \\
\hline Asymmetry of colors & 78.9 & 22.7 & 39.3 & 63.0 & $1.099(0.589-2.051)$ \\
\hline Asymmetry of structures & 78.9 & 16.0 & 37.3 & 54.5 & $0.714(0.370-1.380)$ \\
\hline Ulceration & 36.8 & 96.7 & 87.5 & 70.7 & $16.917(6.326-45.265)$ \\
\hline Pseudolacunae & 24.2 & 98.0 & 88.5 & 67.1 & $15.653(4.549-53.854)$ \\
\hline Blue-white veil & 57.9 & 86.0 & 72.4 & 76.3 & $8.446(4.568-15.67)$ \\
\hline Rainbow pattern & 26.3 & 95.3 & 78.1 & 67.1 & $7.296(3.018-17.687)$ \\
\hline Milky red areas & 35.8 & 89.3 & 68.0 & 68.7 & $4.668(2.395-9.096)$ \\
\hline Blue-black pigmentation & 18.9 & 94.7 & 69.2 & 64.8 & 4.149 (1.724-9.983) \\
\hline Irregular vessels & 43.2 & 83.3 & 62.1 & 69.8 & $3.796(2.102-6.855)$ \\
\hline Shiny white streaks & 54.7 & 70.7 & 54.2 & 71.1 & $2.913(1.702-4.973)$ \\
\hline Structureless brown areas & 15.8 & 88.0 & 45.5 & 62.3 & $1.375(0.656-2.880)$ \\
\hline Negative pigment network & 7.4 & 92.7 & 38.9 & 61.2 & $1.005(0.376-2.690)$ \\
\hline Streaks & 18.9 & 80.0 & 37.5 & 60.9 & $0.935(0.488-1.792)$ \\
\hline Irregular blotches & 42.1 & 49.3 & 34.5 & 57.4 & $0.708(0.422-1.189)$ \\
\hline Irregular globules & 38.9 & 51.3 & 33.6 & 57.0 & $0.673(0.399-1.134)$ \\
\hline Prominent skin markings & 5.3 & 91.3 & 27.8 & 60.4 & $0.585(0.202-1.699)$ \\
\hline Atypical pigmented network & 34.7 & 48.7 & 30.0 & 54.1 & $0.505(0.295-0.856)$ \\
\hline Regression & 25.3 & 54.7 & 26.1 & 53.6 & $0.408(0.238-0.717)$ \\
\hline Hypopigmented areas & 6.3 & 84.7 & 20.7 & 58.8 & $0.372(0.149-0.950)$ \\
\hline
\end{tabular}

Sens. = sensitivity; Spec. = specificity PPV = positive predictive value; NPV = negative predictive value; OR = odds ratio; $\mathrm{CI}=$ confidence interval.

ulceration $(87.5 \%)$ and pseudolacunae $(88.5 \%)$, whereas the other features showed low values. NPV was lower than $80 \%$ for all dermoscopic features. The following colors and structures were associated with melanoma thickness $\geq 0.8 \mathrm{~mm}$ : red-pink $(\mathrm{OR}=4.641)$, blue-gray $(\mathrm{OR}=3.743)$, white $(\mathrm{OR}$ $=3.168)$, blue-white veil $(\mathrm{OR}=8.446)$, shiny white streaks $(\mathrm{OR}=2.913)$, irregular vessels $(\mathrm{OR}=3.796)$, blue-black pigmentation $(\mathrm{OR}=4.149)$, milky red areas $(\mathrm{OR}=4.668)$, pseudolacunae $(\mathrm{OR}=15.653)$, ulceration $(\mathrm{OR}=16.917)$ and rainbow pattern $(\mathrm{OR}=7.296)$. On the other hand, atypical pigmented network $(\mathrm{OR}=5.505)$, regression $(\mathrm{OR}=0.408)$ and hypopigmented areas $(\mathrm{OR}=0.372$ ) were significantly associated with early melanomas.

\section{Discussion}

Argenziano et al [1] reported for the first time in 1997 the differences of colors and dermoscopic structures in a case series of 72 melanomas (41 thin melanomas $<0.75 \mathrm{~mm}, 31$ thick melanomas $\geq 0.75 \mathrm{~mm}$ ). The authors reported a higher frequency of pigment network, radial streaming and white scar-like areas in thin melanomas, whereas gray-blue areas, structural asymmetry and a vascular pattern were more frequent in thick melanomas. A significant association between the presence of a pigment network and thin melanomas was noted, as well as gray-blue areas and a vascular pattern in thick melanomas. These findings were confirmed in a study of 84 melanomas by Stante et al [2].

A few attempts have been made to reliably predict tumor thickness by dermoscopy, such as the clinical-dermoscopic algorithm published in 1999 by Argenziano et al [3]. The authors reported that the combination of palpability, tumor diameter $\geq 15 \mathrm{~mm}$, pigment network, gray-blue areas, and atypical vascular pattern increased the prediction accuracy by $14 \%$ compared to palpability alone and $9 \%$ compared to dermoscopy alone. Others have tried to apply well-known 
dermoscopic algorithms to predict tumor thickness. The $\mathrm{ABCD}$ rule had an adequate performance in predicting tumor thickness in a series of 84 cutaneous melanomas when a total dermatoscopy score (TDS) cut-off of 6.80 was applied [4]. Despite the initially promising results of the preoperative assessment of melanoma thickness by dermoscopy, few studies of this approach have been published since then.

Nomenclature in dermoscopy has expanded over the past decade, and the impact of some dermoscopic structures has not yet been studied. Melanoma guidelines have been updated, and $0.8 \mathrm{~mm}$ is now considered the cut-off between T1a and T1b melanomas [7]. The present study expands on this literature and updates it with updated nomenclature. In addition, our study had a bigger sample than previous studies, and we investigated a larger variety of dermoscopic structures.

The only clinical features that reached statistical significance were tumor size $\geq 10 \mathrm{~mm}$, a slightly lower cut-off than $15 \mathrm{~mm}$ as previously reported [3], and palpability. Although in situ melanomas were all non-palpable and more than $90 \%$ of the $>0.8 \mathrm{~mm}$ thick melanomas were clearly palpable, $46.9 \%$ of the early invasive melanomas $(<0.8 \mathrm{~mm})$ were also palpable. The analysis of this single parameter would have classified these thin melanomas as thick when they were not, and on the contrary, $9.5 \%$ of thick melanomas would have been wrongly classified as thin.
Table 4 presents the colors and structures associated with melanomas $<0.8 \mathrm{~mm}$ and $\geq 0.8 \mathrm{~mm}$. Thin melanomas were associated with light brown color whereas thick melanomas were associated not only with blue-gray color, but also red-pink and white. However, the clinical and dermoscopic evaluation of colors must take into account the area of examination, both histologically and dermoscopically. It is not uncommon for melanomas, especially superficial-spreading subtypes, to present areas of different thickness throughout their width. Thick melanomas may show light brown areas in their periphery, and blue areas in the thicker center that must always be considered.

No statistically significant differences were observed regarding asymmetry of color or structures, unlike a previous study based on digital analysis [8]. This discrepancy might be related to a more rigid interpretation of asymmetry by computerized algorithms than the human eye. Atypical pigmented network, regression and hypopigmented areas were associated with early melanomas here (Figure 1 ) as in previous reports [1,2]. Ulceration, pseudolacunae, blue-white veil, milky red areas, irregular vessels, blue-black pigmentation and shiny white streaks were associated with a melanoma tumor thickness $\geq 0.8 \mathrm{~mm}$ (Figure 2). The latter has already been reported to be associated with thicker melanomas in a case series of 144 melanomas [9]. The evaluation of

Table 4. Significant Associations Between Specific Dermoscopic Features and Breslow Thickness

\begin{tabular}{|l|l|l|}
\hline Colors & \multicolumn{1}{|c|}{ Melanoma $<\mathbf{0 . 8} \mathbf{~ m m}$} & \multicolumn{1}{|c|}{ Melanoma $\geq \mathbf{0 . 8} \mathbf{~ m m}$} \\
\hline Dermoscopic features & Light brown & $\begin{array}{l}\text { Red-pink } \\
\text { Blue-gray } \\
\text { White }\end{array}$ \\
\hline & $\begin{array}{l}\text { Atypical pigmented network } \\
\text { Regression } \\
\text { Hypopigmented areas }\end{array}$ & $\begin{array}{l}\text { Blue-white veil } \\
\text { Shiny white streaks } \\
\text { Irregular vessels } \\
\text { Blue-black pigmentation } \\
\text { Milky red areas } \\
\text { Rainbow pattern } \\
\text { Pseudolacunae } \\
\text { Ulceration }\end{array}$ \\
\hline
\end{tabular}

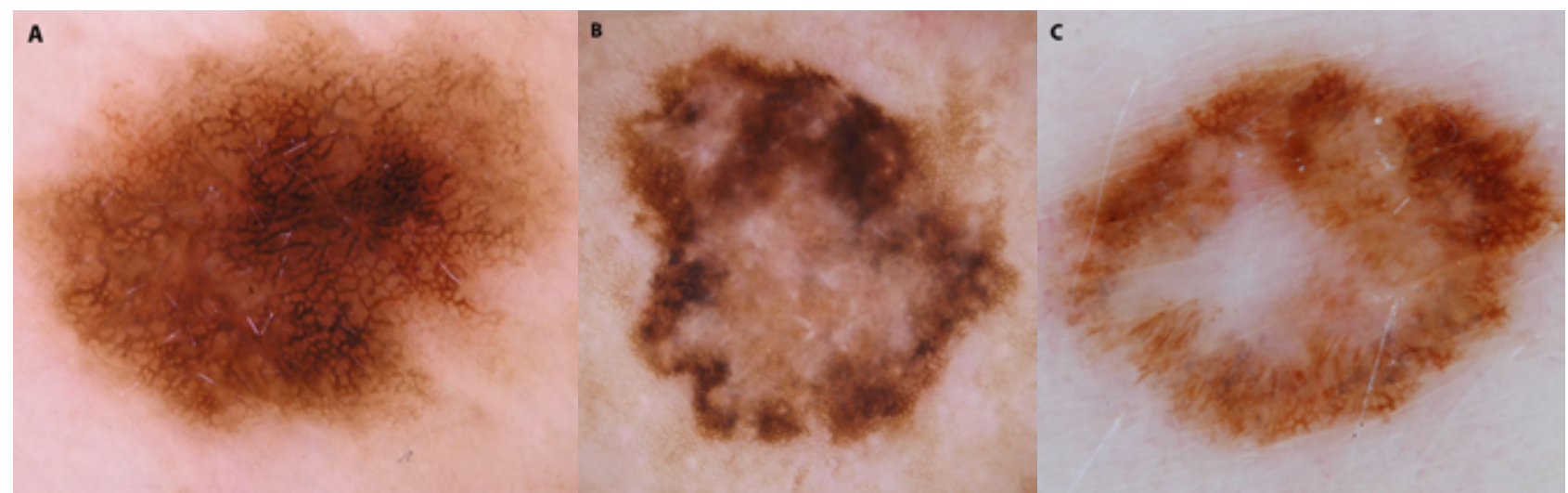

Figure 1. Dermoscopic predictors of thin melanoma ( $<0.8 \mathrm{~mm}$ tumor thickness). (A) Atypical pigmented network. (B) Regression. (C) Hypopigmented areas. 


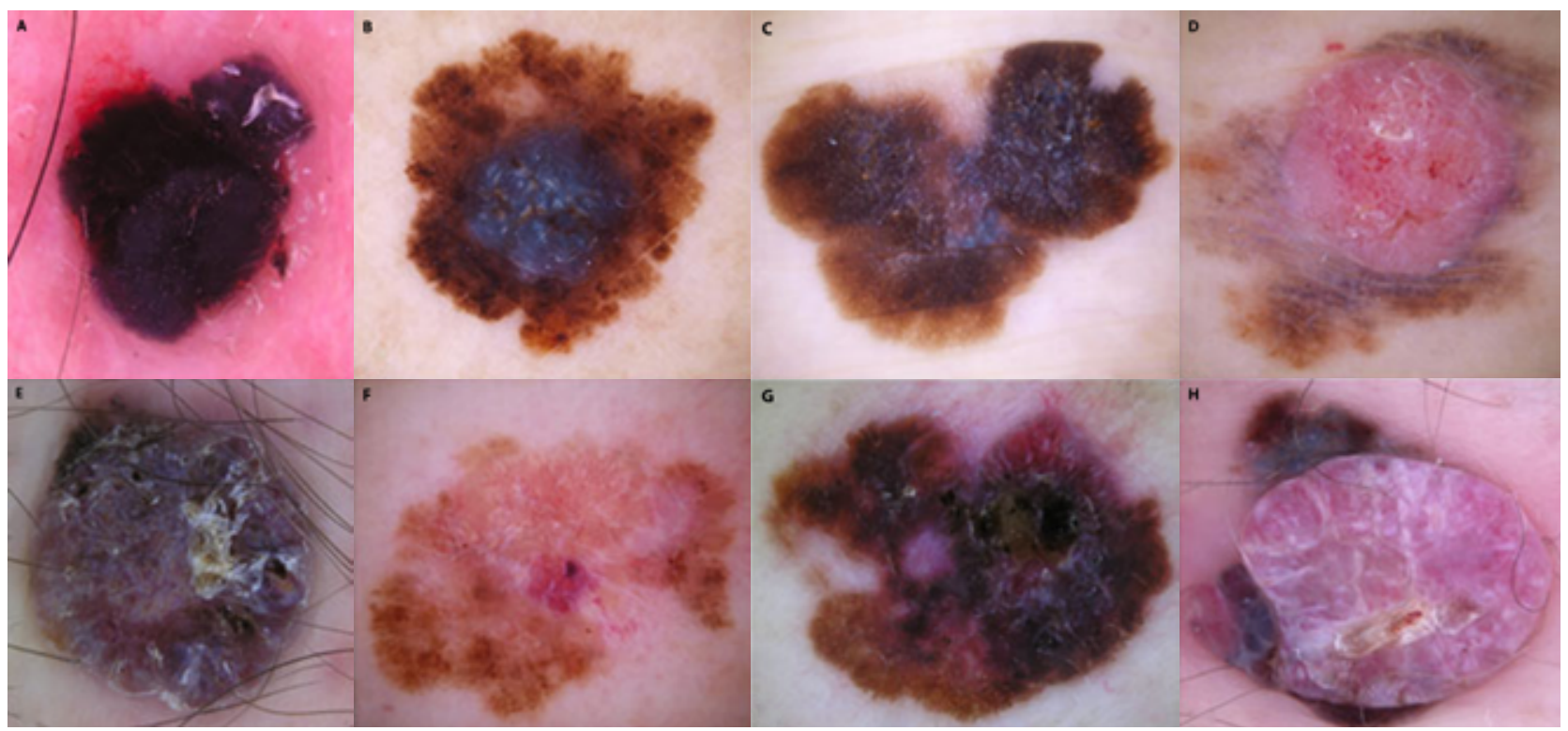

Figure 2. Dermoscopic predictors of thick melanoma ( $\geq 0.8 \mathrm{~mm}$ tumor thickness). (A) Blue-black pigmentation. (B) Blue-white veil. (C) Shiny white streaks. (D) Irregular vessels. (E) Rainbow pattern. (F) Milky red areas. (G) Ulceration. (F) Pseudolacunae.

dermoscopic structures should consider the same principles mentioned previously in color evaluation.

Mun et al [10] recently reported the dermoscopic differences between thin and thick acral melanomas ( $<2 \mathrm{vs} .>2 \mathrm{~mm}$ ) in a cohort of 75 cases. The authors concluded that blue (OR $=7.09)$, white $(\mathrm{OR}=5.04)$, atypical vessels $(\mathrm{OR}=34.58)$, blue-white veil $(\mathrm{OR}=9.60)$ and ulceration $(\mathrm{OR}=5.08)$ were associated with thick acral melanomas. While our study specifically excluded acral melanomas, most of our results are consistent with theirs.

The combination of dermoscopy and other imaging techniques such as optical coherence tomography, multispectral imaging and high-frequency ultrasonography could further enhance the preoperative assessment of melanoma patients towards "personalized medicine". Together with palpability and these specific dermoscopic findings, they could allow a fairly precise tumor thickness prediction. However, caution is recommended before the excision of early melanomas in a single surgical procedure. To date, clinical guidelines do not have a recommendation for this approach, and further evidence is required before standardization. It should be limited to cases with a high malignancy suspicion, and not done in doubtful cases, in order to minimize the risk of causing unnecessary, large scars in benign lesions. The benefits and risks of performing a single-step surgery on a patient need to be adequately addressed before proceeding.

Limitations of our study are its retrospective nature and single-institution design. Melanomas of special sites were excluded from our evaluation. Dermoscopy is based on subjective evaluations that depend largely on the observers' experience. Larger prospective studies focusing on the reliability of the combination of certain colors and structures are required to confirm and validate our findings.

\section{Conclusions}

Certain dermoscopic structures and colors might help in the discrimination between thin and thick melanomas. Although none of them are entirely specific to either group, the combination of more than one of them in a single lesion increases the probability of an adequate tumor thickness prediction. For example, pigmented lesions presenting palpable blue-white veil, milky red areas and ulceration are unlikely to be early melanomas. On the other hand, lesions presenting an atypical pigmented network and small foci of regression without any other dermoscopic features are very unlikely to be $>0.8 \mathrm{~mm}$ thickness. The reliability of the combination of certain dermoscopic colors and structures is to be determined, and should be the subject of future studies.

\section{References}

1. Argenziano G, Fabbrocini G, Carli P, De Giorgi V, Delfino M. Epiluminescence microscopy: criteria of cutaneous melanoma progression. J Am Acad Dermatol. 1997;37(1):68-74. DOI: 10.1016/S0190-9622(97)70213-5.

2. Stante M, De Giorgi V, Cappugi P, Gianotti B, Carli P. Non-invasive analysis of melanoma thickness by means of dermoscopy: a retrospective study. Melanoma Res. 2001;11(2):147-152. DOI: 10.1097/00008390-200104000-00009. PMID: 11333124.

3. Argenziano G, Fabbrocini G, Carli P, De Giorgi V, Delfino M. Clinical and dermatoscopic criteria for the preoperative evaluation of cutaneous melanoma thickness. J Am Acad Dermatol. 1999;40(1):61-68. DOI: 10.1016/S0190-9622(99)70528-1.

4. Carli P, De Giorgi V, Palli D, Giannotti V, Giannotti B. Preoperative assessment of melanoma thickness by ABCD score of dermatoscopy. J Am Acad Dermatol. 2000;43(3):459-466. DOI: 10.1067/mjd.2000.106518. PMID: 10954657. 
5. De Giorgi V, Carli P. Dermoscopy and preoperative evaluation of melanoma thickness. Clin Dermatol. 2002;20(3):305-308. DOI: 10.1016/S0738-081X(02)00224-9.

6. Weyers W. "Personalized excision" of malignant melanoma-need for a paradigm shift in the beginning era of personalized medicine. Am J Dermatopathol. 2019;41(12):884-896. DOI: 10.1097/ DAD.0000000000001450. PMID: 31490196.

7. Balch CM, Gershenwald JE, Soong S, et al. Final version of 2009 AJCC Melanoma staging and classification. J Clin Oncol. 2009;27(36):6199-6206. DOI: 10.1200/JCO.2009.23.4799. PMID: 19917835.

8. Rubegni P, Cevenini G, Sbano P, et al. Evaluation of cutaneous melanoma thickness by digital dermoscopy analysis: a retrospec- tive study. Melanoma Res. 2010;20(3):212-217. DOI: $10.1097 /$ CMR.0b013e328335a8ff. PMID: 20375922.

9. Verzi AE, Quan VL, Walton KE, et al. The diagnostic value and histologic correlate of distinct patterns of shiny white streaks for the diagnosis of melanoma: A retrospective, case-control study. J Am Acad Dermatol. 2018;78(5):913-919. DOI: 10.1016/j. jaad.2017.11.021. PMID: 29138058.

10. Mun JH, Jo G, Darmawan CC, et al. Association between Breslow thickness and dermoscopic findings in acral melanoma. J Am Acad Dermatol. 2018;79(5):831-835. DOI: 10.1016/j. jaad.2018.06.004. PMID: 29906546. 